\title{
Pain mechanisms in chronic pancreatitis: of a master and his fire
}

\author{
Ihsan Ekin Demir • Elke Tieftrunk • Matthias Maak • \\ Helmut Friess • Güralp Onur Ceyhan
}

Received: 12 October 2010 / Accepted: 24 November 2010 /Published online: 10 December 2010

(C) The Author(s) 2010. This article is published with open access at Springerlink.com

\begin{abstract}
Background Unraveling the mechanisms of pain in chronic pancreatitis $(\mathrm{CP})$ remains a true challenge. The rapid development of pancreatic surgery in the twentieth century, usage of advanced molecular biological techniques, and emergence of clinician-scientists have enabled the elucidation of several mechanisms that lead to the chronic, complicated neuropathic pain syndrome in CP. However, the proper analysis of pain in CP should include three main arms of mechanisms: "peripheral nociception," "peripheral/pancreatic neuropathy and neuroplasticity," and "central neuropathy and neuroplasticity."

Discussion According to our current knowledge, pain in $\mathrm{CP}$ involves sustained sensitization of pancreatic peripheral nociceptors by neurotransmitters and neurotrophic factors following neural damage. This peripheral pancreatic neuropathy leads to intrapancreatic neuroplastic alterations that involve a profound switch in the autonomic innervation of the human pancreas via "neural remodeling." Furthermore, this neuropathy entails a hyperexcitability of spinal sensory second-order neurons, which are subject to modulation
\end{abstract}

I. E. Demir · E. Tieftrunk • M. Maak $\cdot$ H. Friess •

G. O. Ceyhan $(\bowtie)$

Department of Surgery, Klinikum Rechts der Isar,

Technische Universität München,

Ismaninger Str. 22,

81675, Munich, Germany

e-mail: ceyhan@chir.med.tu-muenchen.de

I. E. Demir

e-mail: demir@chir.med.tu-muenchen.de

E. Tieftrunk

e-mail: tieftrunk@chir.med.tu-muenchen.de

M. Maak

e-mail: maak@chir.med.tu-muenchen.de

H. Friess

e-mail: friess@chir.med.tu-muenchen.de from the brainstem via descending facilitation. Finally, viscerosensory cortical areas react to this central sensitization via spatial reorganization and thus a central neuroplasticity. The present review summarizes the current findings in these arms of mechanisms and introduces a novel concept to consistently describe pain in $\mathrm{CP}$ as a "predominantly neuropathic," "mixed-type" pain.

Keywords Chronic pancreatitis · Pain · Peripheral pancreatic neuropathy $\cdot$ Neural remodeling $\cdot$ Sensitization . Temporal summation $\cdot$ EEG $\cdot$ Spinal hyperactivity

\section{Introduction}

Schmerz ist ein Meister, der uns klein macht,

Ein Feuer, das uns ärmer brennt,

Das uns vom eigenen Leben trennt,

Das uns umlodert und allein macht.

Pain is a master that renders us small,

A fire that burns us to vanity,

One that separates us from our own lives,

One that lights us up and makes us alone.

One of the major features of the poem above by the SwissGerman Nobel laureate poet Hermann Hesse (1877-1962) is the attribution of the trait of a "master" and a detrimental "fire" to pain [1]. Indeed, there are probably no better words to describe the eminence of pain in the lives of patients, a problem that clinicians encounter daily in their clinical practice. Regardless of its origin and the underlying disease, chronic, enduring pain is a genuine challenge both to the sufferer and the treating physicians. The poorly understood mechanisms of pain generation and treatment reflect them- 
selves even more in the context of pain originating from visceral organs. If one had to pick a single visceral disorder that literally reigns over the lives of the patients exactly the same way as described by Hesse, then this would most likely be the tormenting pain due to chronic pancreatitis (CP). Reported by at least $80-94 \%$ of patients with $\mathrm{CP}$, chronic pain due to $\mathrm{CP}$ is typically a burning, intermittent, and shooting pain, often resulting in narcotic addiction [2,3]. Advances in molecular biology, enhanced access to human pancreatic specimens owing to the increased emergence of "pancreatic surgeons," and the integration of pain specialists into research and treatment related to this excruciating pain have recently revealed numerous mechanisms that are thought to spark it. In general, these mechanisms can be classified according to their location or their relation to nerve damage. Hence, one can differentiate between "peripheral" and "central" mechanisms of pain in CP. However, what seems to overhang these two is the classification into "nociceptive" mechanisms, characterized by direct stimulation of intact nerve fibers by the responsible agents, and into "neuropathic" ones in the presence of nerve damage. This review summarizes the current findings on pain in $\mathrm{CP}$ in three arms of mechanisms (Fig. 1) and introduces a novel concept to consistently describe pain in $\mathrm{CP}$ as neither solely nociceptive nor only neuropathic, but rather as a "mixed-type" pain.

\section{Peripheral nociceptive mechanisms: is there really a direct activation?}

In order to induce nociception, substances or noxi capable of stimulating nociceptive neurons should get into contact
Fig. 1 Main actors in the generation of pain in chronic pancreatitis $(\mathrm{CP})$. The neuropathic pain syndrome in $\mathrm{CP}$ involves numerous molecular and morphological alterations at intrapancreatic (peripheral) and extrapancreatic (dorsal root ganglia/DRG, spinal cord, brainstem, and cerebrum) sites. The increased presence of nociceptive signals in the periphery as mediated by neurotransmitters and neurotrophic factors is paralleled by prominent neural damage and numerous intrapancreatic neuropathic/neuroplastic alterations. At the same time, DRG and spinal cord neurons exhibit a hypersensitive state which is subject to modulation from the brainstem over descending facilitation. Finally, the cerebral cortex adapts to these caudal alterations by increasing its basal activity and changing its spatial conformation in viscerosensory areas. Please refer to the manuscript for further details and the respective references

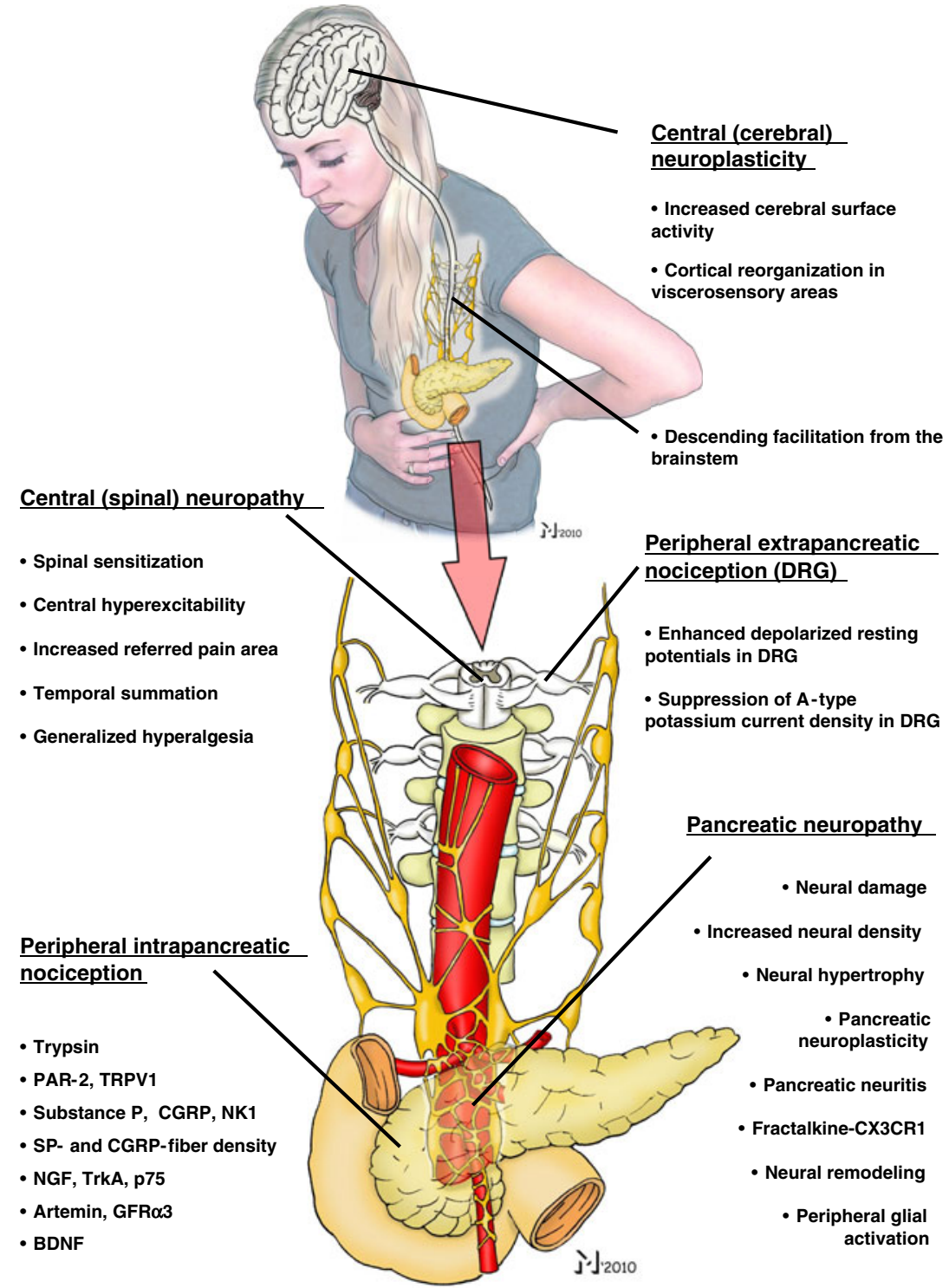


with nociceptive, i.e., C- or A $\delta$-type, nerve fibers. One of the main gaps in our knowledge on pain mechanisms in $\mathrm{CP}$ is that we still do not know what factors actually activate the intrapancreatic nociceptors. Older studies originally suggested ductal hypertension due to constriction or calculi, increased intraparenchymal pressure as a result of fibrosis, or toxic substances like alcohol as potential stimulators of these receptors $[4,5]$. However, none of these factors has ever been proven to be directly associated with pancreatic pain, and even in the absence of these factors, CP patients are frequently victims of severe pain $[4,6-8]$. Still, there seems to be a peculiarity of alcohol-induced $\mathrm{CP}$ as opposed to $\mathrm{CP}$ etiologies like biliary, idiopathic, and $\mathrm{CP}$ due to rare etiologies (hereditary, etc.): In an unpublished study, we analyzed the degree of pain among 211 patients with different CP etiologies (Table 1). Obviously, patients with alcohol-induced CP indeed had significantly $(p<0.01)$ higher degrees of pain than patients with $\mathrm{CP}$ due to other etiologies (Table 1). As of today, there are no studies that could provide a pathomechanistic explanation for this clinical observation.

As CP is, in part, the result of recurrent attacks of acute pancreatitis, substances that are thought to initiate acute attacks of pancreatitis have also been the focus in terms of their potential to trigger pain in CP. It has been suggested that agents like protons, bradykinin, hydrogen sulfide, serotonin, and calcium that are released after damage to acinar cells result in activation of nociceptive fibers via their respective receptors [9]. However, it is crucial to note that the direct activation of nociceptive fibers due to these molecules has never been demonstrated in any animal model of CP or in human CP. Therefore, the activation of nociceptive fibers via these molecules in $\mathrm{CP}$ is still a theoretical assumption. In contrast, there are only two

Table 1 Pain degree in relation to chronic pancreatitis (CP) etiology

\begin{tabular}{lccc}
\hline $\begin{array}{l}\text { Etiology } \\
\text { of CP }\end{array}$ & No pain & Mild pain & $\begin{array}{c}\text { Moderate to } \\
\text { severe pain }\end{array}$ \\
\hline $\begin{array}{c}\text { Alcoholic } \\
(n=78)\end{array}$ & 4 & 24 & 50 \\
$\begin{array}{c}\text { Biliary } \\
(n=23)\end{array}$ & 7 & 4 & 12 \\
$\begin{array}{c}\text { Idiopathic } \\
(n=60)\end{array}$ & 14 & 23 & 23 \\
$\begin{array}{c}\text { Other } \\
(n=50)\end{array}$ & 6 & 14 & 30 \\
\hline
\end{tabular}

The individual pain score of $211 \mathrm{CP}$ patients (i.e., pain intensity and frequency) was prospectively registered prior to surgical resection. Pain intensity was graded by using a short scale: $0=$ none, $1=$ mild, $2=$ moderate, and $3=$ strong pain. Pain frequency was graded as $3=$ daily, $2=$ weekly, and $1=$ monthly. To calculate the degree of pain, pain intensity and pain frequency of each individual were multiplied. According to the final pain score, the patients were divided into three groups: no pain (0), mild pain (1-3), and moderate to severe pain (4-9) nociceptive receptors that are found in the pancreas and have been shown to be directly stimulated by such substances: proteinase-activated receptor 2 (PAR-2) and transient receptor potential vanilloid 1 (TRPV1; Fig. 1). In their study, Hoogerwerf et al. showed that trypsin infusion into the pancreatic duct of rats induces activation of sensory dorsal root ganglia (DRG) neurons by binding to the PAR-2 as measured by their increased FOS immunoreactivity [10]. It should be noted that this study employed a behavioral testing model instead of a CP model to demonstrate this effect. In another important study, Xu et al. treated rats with trinitrobenzene sulphonic acid (TNBS) to induce CP and recorded significantly more depolarized resting potentials and suppression of A-type potassium current density in pancreas-specific DRG neurons than in controls [11]. This evidence for the activation of nociceptive fibers was further supported by the increased TRPV1 expression and enhanced capsaicin responsiveness of pancreas-specific DRG neurons in their CP model [11]. Furthermore, it is also known that some of the inflammatory mediators stated above can also indirectly activate TRPV1 by lowering its activation threshold [12].

Due to the difficulties in identifying the direct activators of nociceptive fibers in $\mathrm{CP}$, what has become another means of investigating the nociceptive mechanisms of pain in $\mathrm{CP}$ was the assessment of nociceptive activation markers in CP. Once activated, nociceptive nerve fibers secrete enhanced amounts of neurotransmitters like glutamate, substance $P$, and calcitonin gene-related peptide (CGRP) into the pancreas in an anti-dromic fashion (Fig. 1). The release of these mediators results in local inflammation due to the vasodilatory and chemotactic effect of these mediators for inflammatory cells. This concept of "neurogenic inflammation" as orchestrated by peripheral nociceptive fibers has been thoroughly studied in experimental acute pancreatitis $[13,14]$. In CP, the involvement of neurogenic inflammation is more difficult to prove, in part due to the short-lived action of these neurotransmitters. However, Büchler et al. could already show in a semi-quantitative analysis the upregulation of SP- and CGRP-immunoreactive nerve fibers in human CP specimens (Fig. 1) [15]. A subsequent study tried to verify this finding by comparing the tissue levels of the SPexpressing gene preprotachykinin A (PPT-A) in normal pancreas (NP) and CP [16]. Strikingly, this study did not detect any difference in terms of PPT-A expression in NP and $\mathrm{CP}$ and therefore attributed the source of SP in CP to an extrapancreatic location, e.g., to the DRG [16]. While the exact role of SP in CP-associated nociception deserves further investigation, another study demonstrated the upregulation of its receptor neurokinin-1 (NK-1R) in nerves and infiltrating inflammatory cells. Of importance, the expression of NK-1R correlated with the intensity and frequency of abdominal pain of CP patients [17]. 
A major set of nociceptive activation markers under investigation is the vast family of neurotrophic factors. Of these, nerve growth factor (NGF) has been the first suspect in terms of nociception. Especially, NGF is known to activate nociceptive nerve fibers and modulate SP expression via its high-affinity receptor TrkA and its low-affinity receptor p75 [18]. We could previously demonstrate the overexpression of NGF in CP tissue, mainly localized to hypertrophic nerves, intrapancreatic ganglia, metaplastic ductal cells, and degenerating acinar cells [19]. On the other hand, while we detected no correlation between NGF expression and pain sensation of CP patients, TrkA was strongly expressed in the perineurium, and its mRNA expression was strongly related to the degree of pain of $\mathrm{CP}$ patients (Fig. 1) [19]. These findings on NGF ushered in a subsequent study that demonstrated a similar upregulation and pain correlation for the brain-derived neurotrophic factor (BDNF) [20], which also exerts prominent nociceptive effects by acting on the p75 receptor and the sphingomyelin pathway [21]. These pioneering findings demonstrating the role of neurotrophic factors in CP-related peripheral nociception gained a novel dimension following the analysis of the glial cell-line derived neurotrophic factor (GDNF) family member artemin and its receptor GFR $\alpha 3$ (Fig. 1) [22]. It is known that artemin, especially in conjunction with NGF, can induce hyperalgesia [23]. In $\mathrm{CP}$, both artemin and GFR $\alpha 3$ were significantly overexpressed, but interestingly, mainly located in Schwann cells, intrapancreatic ganglia, and smooth muscle cells of arteries (Fig. 1). While the amount of artemin expression by nociceptive nerve fibers has not yet been quantified, there is a strong correlation between its expression and the pain severity. Hence, the activation of nociceptive/sensory DRG neurons to produce artemin would lead to the retrograde axonal transport of artemin in sensory afferents towards the pancreas, as it is known for SP, CGRP, but also for other GDNF family members [24]. The natural question that arises out of this assumption is what effects neurotrophic factors exert in pancreatic tissue. Due to their trophic attributes, one can assume that they can induce the growth of nerves or neural components. This assumption has indeed been crucial for the understanding of "neuropathy" in CP and helped to establish the link between nociception and neuropathy in $\mathrm{CP}$, as described below.

\section{Peripheral neuropathic mechanisms: pancreatic neuropathy as a prototype of visceral neuropathy}

In order to understand "pancreatic neuropathy," one should carefully analyze the historical evolvement of this research field. The motivation to investigate the above-mentioned peripheral nociceptive mechanisms is in part derived from parallel studies on acute pancreatitis. On the other hand, the currently accepted notion of neuropathy in $\mathrm{CP}$ and other pancreatic disorders has its roots in the initial recognition of neural alterations in histopathological specimens. Keith et al. for the first time reported prominent infiltration of intrapancreatic nerves in $\mathrm{CP}$ by inflammatory cells and especially eosinophils [25]. Strikingly, they found a major correlation of pain with the percentage of eosinophilic infiltration around these nerves [25]. In a subsequent detailed study, Bockman et al. found out that nerves in $\mathrm{CP}$ undergo an increase in their density and a hypertrophy. However, what is even more important, they conducted an ultrastructural analysis of intrapancreatic nerves in $\mathrm{CP}$ and observed severe neural damage, as evidenced by disrupted perineurium, edematous neural contents, and penetration of inflammatory cells into the interior of nerves [4]. Unfortunately, the importance of these observations remained unrecognized until the advent of larger studies that demonstrated a key correlation between the extent of neural damage, neural sprouting, neural hypertrophy, the inflammation around nerves (termed "pancreatic neuritis"), and the pain frequency and intensity of CP patients $[22,26]$. This fundamental correlation laid the foundation for the increased realization of pancreatic neuropathy and neuropathic pain in $\mathrm{CP}[22,26]$ because neuropathic pain, as suggested by the Neuropathic Pain Special Interest Group of the International Association for the Study of Pain (NeuPSIG), is defined as "pain arising as direct consequence of a lesion or disease affecting the somatosensory system" [27].

As pancreatic neuropathy increasingly drifted into the attention of researchers, it resulted in the parallel emergence of another cardinal concept, i.e., pancreatic neuroplasticity. The damage to intrapancreatic nerves indeed seems to be accompanied by numerous peripheral neuroplastic changes, as best evidenced by the prominent hypertrophy and sprouting of intrapancreatic nerves (Fig. 1). Investigation of the well-established neural plasticity marker growth-associated protein 43 (GAP-43) in $\mathrm{CP}$ confirmed this phenomenon owing to its overexpression in CP tissue $[26,28]$. This plasticity gained a further fascinating dimension after investigation of the autonomic innervation of the pancreas in $\mathrm{CP}$ when compared to NP [29]. When the sympathetic and parasympathetic innervations of the pancreas were compared between CP and NP, there was a conspicuous decrease in the pancreatic sympathetic innervation in CP. At first glance, the parasympathetic innervation did not demonstrate any major difference between $\mathrm{CP}$ and NP, but importantly, both sympathetic and parasympathetic innervations were even more severely diminished in $\mathrm{CP}$ patients who suffered from severe neuropathic abdominal pain and/or severe pancreatic neuritis [29]. 
When analyzing peripheral nerves, what must be taken into consideration are not only the neuronal components but also the state of the glia cells, i.e., Schwann cells, in these nerves. The above-mentioned study aimed not only at investigating the autonomic innervation in $\mathrm{CP}$ but also at dissecting the role of Schwann cells in these altered nerves. Glia cells are increasingly believed and shown to play a pivotal role in neuropathic pain, especially due to inflammatory disorders [30]. In order to get an idea of their activation state, we previously quantified the expression of the glial transcription factor Sox10 and the neuroepithelial stem cell marker Nestin in CP. In accordance with the axioms of neuropathy, the activation state of glia in $\mathrm{CP}$ was dramatically different: Intraneural Sox10 expression in CP was extremely diminished, whereas there was a florid increase in the intraneural Nestin immunoreactivity. These findings helped to draw the first image of glia in pancreatic neuropathy and are therefore of crucial significance. As a response to nerve injury, Schwann cells start to proliferate, undifferentiate, and promote axonal growth, remyelination, and sensitization of nociceptors via release of neurotrophic agents [30]. As Sox10 is continuously present in mature Schwann cells $[30,31]$, decreased Sox10 expression in nerves in CP is most likely an indicator of a reduction in the number of mature Schwann cells, possibly due to the above-mentioned reactive undifferentiation. This interpretation is in line with the observed Nestin upregulation since glial Nestin re-expression and subsequent neural sprouting have been previously demonstrated after denervation of muscles at the neuromuscular junction [32]. Therefore, the alterations in Sox10 and Nestin in pancreatic neuropathy are, although indirect, still clear indicators of glial activation (Fig. 1), as known for various neuropathies [33].

Overall, by looking at these neuropathic alterations in CP involving three main axes, i.e., autonomic innervation changes, glial activation, and associated neuropathic pain, we can say that pancreatic neuropathy is characterized by a "neural remodeling" [29, 34]. This profound alteration in nerves supplying the pancreas may also be considered as a factor in the dissatisfaction with results of pancreatic "denervation" techniques that are used to treat pain in CP [35]. Clinicians tend to believe that denervating the pancreas, especially from the pain-transmitting fibers, can be a therapeutic option. Until today, the denervation has so far been undertaken at the level of celiac ganglion, splanchnic nerves, or the pancreas itself [35]. Regarding the techniques targeting at the celiac ganglion and splanchnic nerves, unfortunately, the overall success rate and effectiveness of celiac plexus blockade (CPB), celiac plexus neurolysis $(\mathrm{CPN})$, and bilateral surgical trans-section of splanchnic nerves ("bilateral splanchnicectomy") remain unsatisfactory. Although around $50 \%$ of the patients experience major pain relief briefly after these interven- tional procedures, the mean post-interventional pain-free interval does not exceed 2-4 months, and lack of follow-up after these 4 months is a common denominator of all these studies. Furthermore, therapy failure is frequent in patients with extensive peripancreatic fibrosis, and investigators controversially defined pain relief as "no need for opioids" [36-39]. Therefore, placebo-controlled, randomized clinical trials are desperately needed to judge the true impact of these interventions to treat pain in CP [34]. In fact, looking at the neural remodeling in $\mathrm{CP}$, these unsatisfying results may not totally be a surprise. In particular, seeing the prominent decrease in the amount of sympathetic nerve fibers that run together with sensory fibers in splanchnic nerves, one should ask about the distribution and amount of sensory/nociceptive fibers in splanchnic and celiac plexus nerves in CP patients. As previously suggested, it is possible that pain in $\mathrm{CP}$ is transmitted via afferents other than the ones running with splanchnic nerves, e.g., with vagal or somatosensory afferents reaching the DRG [29, $35]$. We are convinced that this anatomic remodeling may be the underlying reason for the poor success of denervation procedures to treat pain in CP. However, it is also well known that the most effective pain relief for $\mathrm{CP}$ patients occurs following surgical resection of the pancreatic head (e.g., duodenum-preserving pancreatic head resection and classical pancreaticoduodenectomy), as proven by numerous controlled trials [40-46]. Therefore, it is conceivable that intervening at the origin of pancreatic neuropathy, i.e., the intra-organ intervention, is more effective than surgical or chemical ablation of nerve fibers, which may per se not be the actual paths of pain transmission.

The interdependence between the extent of pancreatic neuropathy, neural remodeling, and pancreatic neuritis should also draw our attention once again to the role of neuro-inflammation in the generation of this peripheral visceral neuropathy. The actors that plot and produce pancreatic neuritis are still unknown. From dozens of known inflammation markers, it is only interleukin 8 (IL-8) which has been studied and shown to be overexpressed in CP tissues in comparison to NP, mainly originating from inflammatory cells infiltrating hypertrophic nerves [16]. However, what factors attract inflammatory cells to nerves and thereby mediate neural damage and neuropathic pain? As an attempt to answer this key question, we previously scrutinized neuron-derived chemoattractants, i.e., neuronal chemokines. The prototype for such molecules is the chemokine fractalkine [47]. Fractalkine harbors three main attributes that turn it into a major suspect to induce the above-described neuropathic alterations in CP: It is a chemoattractant for immune cells, induces neuropathic pain via glial activation, and contributes to tissue fibrosis [48-50]. In $\mathrm{CP}$, we not only detected an overexpression of tissue fractalkine and its receptor CX3CR 1 on 
protein level but also an increased mean nerve immunoreactivity for fractalkine and CX3CR1 in patients suffering from severe neuropathic pain and pancreatic neuritis [47]. Moreover, these alterations were even more pronounced among patients who suffered from neuropathic pain for already longer periods [47]. Thereby, we could for the first time identify a molecular counterpart for the neuro-affinity of inflammatory cells as induced by neuronal molecules. We are convinced that blockade of CX3CR1 may be of substantial benefit in terms of improvement of intrapancreatic and neural inflammation and abdominal neuropathic pain sensation [49]. As of today, further studies investigating other cytokines or chemokine-receptor duos in $\mathrm{CP}$ are still needed.

Looking at the "whole picture" of pancreatic neuropathy, the recent discoveries in this field point to a collective contribution of numerous cellular and molecular actors in the generation of the neuropathic pain in CP: immune cells, damaged nerves, neurogenesis, activated glia, chemokines, cytokines, and possibly even several other unidentified mediators. To our knowledge, despite existence of similar alterations in some other gastrointestinal (GI) disorders like Crohn's disease or ulcerous colitis, there is no other GI disorder than $\mathrm{CP}$ and pancreatic cancer where the association between these neuropathic alterations and the extent of neuropathic pain sensation has been this thoroughly demonstrated. By describing these peripheral nociceptive mechanisms in $\mathrm{CP}$, we are hereby making an appeal to consider these as a motivation to investigate similar alterations in other GI diseases. Nevertheless, it is plausible to assume that a similar remodeling and pain mechanism may exist in many other GI disorders, and that pancreatic neuropathy is in fact a prototype for a more global visceral neuropathy $[29,51]$. The recognition of this possibility would undoubtedly have major implications for the therapy of neuropathic pain in CP and other GI diseases.

\section{Central neuropathic and neuroplastic mechanisms: increased interest in evidence is evidence of increased interest}

The demonstration of the peripheral neural damage in $\mathrm{CP}$ has paved the path to the inauguration of the term "pancreatic neuropathy" as a novel subtype of peripheral visceral neuropathy. It is very encouraging to see that the discovery of these alterations has recently been paralleled by a number of valuable studies that have tried to verify the neuropathic pain syndrome in $\mathrm{CP}$ at the level of the central nervous system (CNS). As stated above, in the presence of peripheral neural damage, nerves become prone to noxious stimuli from their surroundings and secrete factors that can further sensitize nociceptors, e.g., neurotransmitters like glutamate, SP, CGRP, or neurotrophic factors like NGF,
BDNF, and artemin. This continuous sensitization of peripheral nociceptors results in simultaneous sensitization of spinal neurons that transmit the peripheral signals to the brain [52]. This global sensitization is a hallmark of neuropathic pain syndromes (Fig. 1) [52]. As a result of this sensitization, it is assumed that the cardinal symptoms of neuropathic pain, i.e., allodynia (pain sensation after non-noxious stimuli) and hyperalgesia (increased pain sensation upon a normal pain stimulus), occur [52]. Briefly, in the presence of continuous nociceptive input, spinal dorsal horn neurons in the lamina II (substantia gelatinosa) of the spinal cord that transmit nociceptive signals to brain start to fire more action potentials due to some crucial mechanisms: (1) long-term potentiation (LTP) of synaptic strength via enhanced presynaptic transmitter release or postsynaptic transmitter effect, (2) changes in membrane excitability due to lower resting membrane potential or lower threshold for action potentials, (3) changes in action potential morphology due to enhanced sodium and depressed potassium currents, (4) reduced strength of synaptic inhibition by inhibitory interneurons, (5) disturbed balance of descending excitation and inhibition, (6) sprouting of fine primary afferents, (7) opening of postsynaptic excitatory pathways from deeper dorsal horn regions (sprouting of $A \beta$-fibers towards lamina II), and (8) phenotypic switch in A fibers that normally transmit only mechanical stimuli (recruitment of $\mathrm{A} \beta$-fibers to produce SP) [53].

While proving these mechanisms in human $\mathrm{CP}$ or even in animal models represents a true technical challenge, clinicians have recently made use of keen techniques to at least assess the symptomatic consequences of such a hyperexcitability in CP patients. The clinical signs of such a central hyperexcitability include the following:

1. increase in the "referred pain" area due to convergence of afferent fibers from different visceral and somatic organs on the same hyperexcitable spinal (secondorder) neurons [54]

2. "temporal summation," i.e., repeated stimuli become increasingly painful in spite of unchanged stimulus intensity [55]

3. generalized hyperalgesia [55]

In a pioneering study, Dimcevski et al. performed a multimodal and multi-tissue stimulation in CP patients to see if there is any increase in the referred pain area, and thus the sensory response of visceral and somatic organs in CP patients [56]. Specifically, they assumed that $\mathrm{CP}$ patients would also harbor a convergence of afferent signals from somatic (skin) and visceral (esophagus) organs, and that the noxious stimulation of these organs would provide a picture of the central hyperexcitability. As hypothesized, they detected a major difference in the pain response of $\mathrm{CP}$ patients and controls following single and repeated electrical stimulation 
in CP patients [56]. This difference reflects the presence of a key feature of neuropathic pain syndromes in CP, i.e., temporal summation [54]. In addition, the investigators demonstrated a major increase in the referred pain area of CP patients ( $30.1 \mathrm{~cm}^{2}$ in $\mathrm{CP}$ vs. $7.7 \mathrm{~cm}^{2}$ in controls), thereby proving the two cardinal features of neuropathic pain syndromes in the context of CP. What remains controversial are their findings on the "algesia"- -status of the patients: They found that CP patients actually had a hyposensitivity to mechanical stimulation in their skin, duodenum, and esophagus [56, 57]. The authors argued that chronic organic GI diseases like Crohn's disease, esophagitis, and peptic ulcer have also been shown to bear hypoalgesia to mechanical stimulation [56-59]. In contrast, Buscher et al. demonstrated that CP patients show pronounced generalized deep hyperalgesia even in the presence of opioid therapy $[60,61]$. The precise interpretation of these contradictory findings is difficult due to the complex pathophysiology of central pain processing. What is more, it is equally hard to explain the peripheral hypoalgesia of $\mathrm{CP}$ patients as reported by Dimcevski et al. in the presence of central hyperexcitability and increased referred pain area. However, what looks like certain is that CNS, especially higher-order centers like brainstem, has a major modulatory impact on the neuropathic pain of CP patients. This so-called "descending inhibitory control" is known to be activated in the presence of continuous painful stimuli which lead to a reactive suppression of spinal neuron activity in the dorsal horn (diffuse noxious inhibitory control/DNIC) [62, 63]. Although it was suggested that $\mathrm{CP}$ patients may rather have a descending inhibition [9, 56, 57], recent findings do not necessarily support this assumption. The involvement of a descending "facilitation" in CP was demonstrated in an elegant study by Vera-Portocarrero et al.: There, the investigators depleted in a rat $\mathrm{CP}$ model the brainstem cells that are responsible for descending modulation by a single local injection of dermorphin-saporin and observed that the maintenance, but not the expression, of CP-associated abdominal hypersensitivity could be prevented [64]. In another very recent study, the involvement of such a descending facilitation rather than an inhibition was verified in CP patients: Upon electrical or heat stimulation in the rectosigmoid region, CP patients demonstrated a remarkable remote hyperalgesia when compared to controls [65]. Therefore, the assumption that organic GI disorders always exhibit hypoalgesia due to DNIC $[9,57]$ cannot be verified in the context of CP where there are clear indicators of a generalized hyperalgesia.

The increasing interest in discovering evidences for the neuropathic character of pain in CP can also be well seen in studies focusing on cerebral pain processing. In one of the first studies related to this field, the investigators performed an endoscopic electrical stimulation of esophagus, stomach, and duodenum of $\mathrm{CP}$ patients and simultaneously recorded event-related brain potentials (ERBPs) via electroencephalogram (EEG) [66]. Remarkably, the early ERBP components that signify the exogenous brain pain processing had a significantly lower latency in CP patients than in controls. In the subsequent analysis, these ERBPs could be localized to the typical viscero-sensory areas of the cerebral cortex, i.e., the bilateral insula, the anterior cingulate gyrus, and the bilateral secondary somatosensory areas. Very interestingly, the bilateral insular dipoles drifted more medially and the cingulate cortex towards more posterior in the $\mathrm{CP}$ group [66], which bears the crucial implication that there is a reorganization of the cerebral cortex in $\mathrm{CP}$ patients. In a further study, the investigators provided further proof for the neuropathic character of the pain syndrome in CP by demonstrating an increased theta wave activity on EEG, a phenomenon which is typical for neuropathic pain [67]. In another study, Fregni et al. demonstrated increased glutamate levels and thus overactivity in the right secondary somatosensory cortex as measured by magnetic resonance spectroscopy [68]. Essentially, there is upcoming firm evidence for a CNS remodeling and modified CNS activity in $\mathrm{CP}$ as a hallmark of a neuropathic pain syndrome.

\section{Mechanism-based pain treatment in chronic pancreatitis: where to go from here now?}

Seeing the neuropathic character of pain in $\mathrm{CP}$, researchers started to share their recent experience regarding the usage of neuropathic pain medications like gabapentin and tricyclic antidepressant to treat pain in CP [9]. Furthermore, it has also been suggested that analgesics which act on $\kappa$-type opioid receptors in addition to the $\mu$-type receptors may bring additional benefit to treat pain in $\mathrm{CP}[9,69]$ : The $\mathrm{K}$-receptors are not only upregulated in inflammatory states but K-receptor antagonists have also been successful in treating pain of CP patients [9, 69]. Although randomized clinical trials testing these neuropathic pain medications are eagerly awaited, we in our hospital have equally made effective use of such medications in refractory cases. Still, looking at the current level of evidence, there is substantial reason to advocate surgery and especially pancreatic head resection for pain in $\mathrm{CP}$ that is refractory to conservative medical analgesic treatment [6]. However, what is the "magic" behind the effectiveness of surgery in the presence of all these central neuroplastic alterations? In other words, how can pain due to $\mathrm{CP}$ be effectively treated by surgery despite an already completed remodeling/reorganization and hyperactivation of the CNS? These questions become even more intriguing if one carefully ponders over the recent findings by Fregni et al.: By using non-invasive repetitive transcranial magnetic stimulation (rTMS) targeting the right secondary somatosensory cortex in patients 
with $\mathrm{CP}$ in a 10-day course, they could achieve a significant analgesic effect for 3 weeks [70]. In addition to being the first study to use rTMS in a visceral disorder, this study should entail offspring studies, which shall verify this effect in larger cohorts. Whether this costly intervention that necessitates repeated rTMS sessions and produces only short-term relief is going to find widespread clinical use remains unclear. We are convinced that elucidation of the central neuroplasticity and aberrant pain processing in $\mathrm{CP}$ makes a major contribution to our understanding of visceral neuropathic pain. However, these fascinating findings should not distract us very much from the importance of once again focusing on the peripheral, "original" cause of this dreadful syndrome. To give an example from a distinct but still very relevant model of neuropathy, Balasubramanyan et al. performed a vast analysis of spinal cord neurons where they compared the electrical properties and excitability of isolated spinal neurons from normal rats with those of rats after sciatic chronic constriction injury [71]. This neuropathic pain model also exhibits noxi-independent pain and abnormal activity in spinal cord neurons in vivo. Very interestingly, the average intrinsic activity of these neurons in spinal cord slices was not nearly as high as always assumed. This observation brought up the key question whether the always assumed central hyperexcitability is not necessarily a "reprogramming" of spinal neurons but rather the result of overactive primary afferents and the continuous release of sensitizers from the peripheral sensory neurons (peripheral activitymaintained central sensitization) [52]. As advocated in the original editorial, the removal of the source of a longstanding pain (e.g., total hip replacement surgery for osteoarthritis, release of an entrapped nerve, and childbirth [52]) may often really be the ultimate solution to chronic pain even in the presence of potential reprogramming. The reversibility of this central hyperactivity may be the key for the success of surgery to treat pain in CP.

\section{Summary and conclusion}

Understanding the mechanisms of pain in $\mathrm{CP}$ remains a true challenge. The breathtaking development of pancreatic surgery in the second half of the twentieth century, emergence of clinician-scientists, and the growing interest of basic scientists and pain specialists enabled the accumulation of considerable information regarding the pathogenesis of this agonizing pain syndrome. Pain in CP should be analyzed to include the three main perspectives of "peripheral nociception," "peripheral/pancreatic neuropathy and neuroplasticity," and "central neuropathy and neuroplasticity." It seems that CP involves sustained sensitization of pancreatic peripheral nociceptors by neurotransmitters and neurotrophic factors following neural damage. This peripheral pancreatic neuropathy leads to intrapancreatic neuroplastic alterations that involve a profound switch in the autonomic innervation of the human pancreas via "neural remodeling." This peripheral neuropathy leads to overactivation of spinal sensory secondorder neurons, which in turn assume a hyperexcitable state. Finally, supraspinal regions in the brainstem and cerebrum exacerbate this caudal hyperactivation via descending facilitation and reorganization to process even more input from the periphery. Therefore, in the case of this neuropathic pain syndrome in $\mathrm{CP}$, there is a clear domination of neuropathic pain mechanisms which, however, in contrast with primary neuropathic syndromes, show a major dependence from the ongoing noxious stimulation from peripheral nociceptors. The effectiveness of surgical removal of the origin of this "nervous system neuropathy" and the resulting clearance of the nociceptors that would otherwise continuously transmit painful stimuli to the CNS represent a crucial peculiarity of this syndrome. Therefore, due the interdependence of nociception and neuropathy in $\mathrm{CP}$, clinicians may consider pain due to CP as a "predominantly neuropathic," "mixed-type" pain. We are convinced that the ideal treatment for pain in $\mathrm{CP}$ can only be achieved via careful consideration of this special mixed mechanism. The fact that pain in CP deserves more intense investigation than ever probably needs no further emphasis, especially if we may leave up the last word again to Hesse: "Der einzige Weg aus der Welt der Schmerzen führt durch den Schmerz hindurch"/"The only way out of the world of pain passes straight through pain itself' [72].

\section{Conflicts of interest None.}

Open Access This article is distributed under the terms of the Creative Commons Attribution Noncommercial License which permits any noncommercial use, distribution, and reproduction in any medium, provided the original author(s) and source are credited.

\section{References}

1. Hesse H (1934) In Schmerzen. Die Neue Rundschau, vol XLV/1. S. Fischer Verlag, Berlin, p 629

2. Andren-Sandberg A, Hoem D, Gislason H (2002) Pain management in chronic pancreatitis. Eur J Gastroenterol Hepatol 14(9):957-970

3. Hatayama K (1978) A clinical investigation of chronic pancreatitiscomparative study between alcoholic pancreatitis and non-alcoholic pancreatitis. Gastroenterol Jpn 13(2):127-139

4. Bockman DE, Buchler M, Malfertheiner P, Beger HG (1988) Analysis of nerves in chronic pancreatitis. Gastroenterology 94 (6):1459-1469

5. Bradley EL 3rd (1982) Pancreatic duct pressure in chronic pancreatitis. Am J Surg 144(3):313-316

6. Ceyhan GO, Michalski CW, Demir IE, Muller MW, Friess H (2008) Pancreatic pain. Best Pract Res Clin Gastroenterol 22(1):31-44 
7. Malfertheiner P, Buchler M, Stanescu A, Ditschuneit H (1987) Pancreatic morphology and function in relationship to pain in chronic pancreatitis. Int J Pancreatol 2(1):59-66

8. Malfertheiner P, Pieramico O, Buchler M, Ditschuneit H (1990) Relationship between pancreatic function and pain in chronic pancreatitis. Acta Chir Scand 156(4):267-270, discussion 270261

9. Drewes AM, Krarup AL, Detlefsen S, Malmstrom ML, Dimcevski G, Funch-Jensen P (2008) Pain in chronic pancreatitis: the role of neuropathic pain mechanisms. Gut 57(11):1616-1627

10. Hoogerwerf WA, Shenoy M, Winston JH, Xiao SY, He Z, Pasricha PJ (2004) Trypsin mediates nociception via the proteinase-activated receptor 2: a potentially novel role in pancreatic pain. Gastroenterology 127(3):883-891

11. Xu GY, Winston JH, Shenoy M, Yin H, Pendyala S, Pasricha PJ (2007) Transient receptor potential vanilloid 1 mediates hyperalgesia and is up-regulated in rats with chronic pancreatitis. Gastroenterology 133(4):1282-1292

12. Wick EC, Hoge SG, Grahn SW, Kim E, Divino LA, Grady EF, Bunnett NW, Kirkwood KS (2006) Transient receptor potential vanilloid 1 , calcitonin gene-related peptide, and substance $\mathrm{P}$ mediate nociception in acute pancreatitis. Am J Physiol Gastrointest Liver Physiol 290(5):G959-G969

13. Liddle RA, Nathan JD (2004) Neurogenic inflammation and pancreatitis. Pancreatology 4(6):551-559, discussion 559-560

14. Nathan JD, Peng RY, Wang Y, McVey DC, Vigna SR, Liddle RA (2002) Primary sensory neurons: a common final pathway for inflammation in experimental pancreatitis in rats. Am J Physiol Gastrointest Liver Physiol 283(4):G938-G946

15. Buchler M, Weihe E, Friess H, Malfertheiner P, Bockman E, Muller S, Nohr D, Beger HG (1992) Changes in peptidergic innervation in chronic pancreatitis. Pancreas 7(2):183-192

16. Di Sebastiano P, di Mola FF, Di Febbo C, Baccante G, Porreca E, Innocenti P, Friess H, Buchler MW (2000) Expression of interleukin 8 (IL-8) and substance $\mathrm{P}$ in human chronic pancreatitis. Gut 47(3):423-428

17. Shrikhande SV, Friess H, di Mola FF, Tempia-Caliera A, Conejo Garcia JR, Zhu Z, Zimmermann A, Buchler MW (2001) NK-1 receptor gene expression is related to pain in chronic pancreatitis. Pain 91(3):209-217

18. Skoff AM, Adler JE (2006) Nerve growth factor regulates substance $\mathrm{P}$ in adult sensory neurons through both TrkA and p75 receptors. Exp Neurol 197(2):430-436

19. Friess H, Zhu ZW, di Mola FF, Kulli C, Graber HU, AndrenSandberg A, Zimmermann A, Korc M, Reinshagen M, Buchler MW (1999) Nerve growth factor and its high-affinity receptor in chronic pancreatitis. Ann Surg 230(5):615-624

20. Zhu ZW, Friess H, Wang L, Zimmermann A, Buchler MW (2001) Brain-derived neurotrophic factor (BDNF) is upregulated and associated with pain in chronic pancreatitis. Dig Dis Sci 46 (8):1633-1639

21. Zhang YH, Chi XX, Nicol GD (2008) Brain-derived neurotrophic factor enhances the excitability of rat sensory neurons through activation of the p75 neurotrophin receptor and the sphingomyelin pathway. J Physiol 586(13):3113-3127

22. Ceyhan GO, Bergmann F, Kadihasanoglu M, Erkan M, Park W, Hinz U, Giese T, Muller MW, Buchler MW, Giese NA, Friess H (2007) The neurotrophic factor artemin influences the extent of neural damage and growth in chronic pancreatitis. Gut 56(4):534-544

23. Malin SA, Molliver DC, Koerber HR, Cornuet P, Frye R, Albers KM, Davis BM (2006) Glial cell line-derived neurotrophic factor family members sensitize nociceptors in vitro and produce thermal hyperalgesia in vivo. J Neurosci 26(33):8588-8599

24. Leitner ML, Molliver DC, Osborne PA, Vejsada R, Golden JP, Lampe PA, Kato AC, Milbrandt J, Johnson EM Jr (1999) Analysis of the retrograde transport of glial cell line-derived neurotrophic factor (GDNF), neurturin, and persephin suggests that in vivo signaling for the GDNF family is GFRalpha coreceptor-specific. J Neurosci 19(21):9322-9331

25. Keith RG, Keshavjee SH, Kerenyi NR (1985) Neuropathology of chronic pancreatitis in humans. Can J Surg 28(3):207-211

26. Ceyhan GO, Bergmann F, Kadihasanoglu M, Altintas B, Demir IE, Hinz U, Muller MW, Giese T, Buchler MW, Giese NA, Friess H (2009) Pancreatic neuropathy and neuropathic pain - a comprehensive pathomorphological study of 546 cases. Gastroenterology 136(1):177-186, e171

27. Treede RD, Jensen TS, Campbell JN, Cruccu G, Dostrovsky JO, Griffin JW, Hansson P, Hughes R, Nurmikko T, Serra J (2008) Neuropathic pain: redefinition and a grading system for clinical and research purposes. Neurology 70(18):1630-1635

28. Fink T, Di Sebastiano P, Buchler M, Beger HG, Weihe E (1994) Growth-associated protein-43 and protein gene-product 9.5 innervation in human pancreas: changes in chronic pancreatitis. Neuroscience 63(1):249-266

29. Ceyhan GO, Demir IE, Rauch U, Bergmann F, Muller MW, Buchler MW, Friess H, Schafer KH (2009) Pancreatic neuropathy results in "neural remodeling" and altered pancreatic innervation in chronic pancreatitis and pancreatic cancer. Am J Gastroenterol 104(10):2555-2565

30. Scholz J, Woolf CJ (2007) The neuropathic pain triad: neurons, immune cells and glia. Nat Neurosci 10(11):1361-1368

31. Kuhlbrodt K, Herbarth B, Sock E, Hermans-Borgmeyer I, Wegner M (1998) Sox10, a novel transcriptional modulator in glial cells. J Neurosci 18(1):237-250

32. Kang H, Tian L, Son YJ, Zuo Y, Procaccino D, Love F, Hayworth C, Trachtenberg J, Mikesh M, Sutton L, Ponomareva O, Mignone J, Enikolopov G, Rimer M, Thompson W (2007) Regulation of the intermediate filament protein nestin at rodent neuromuscular junctions by innervation and activity. J Neurosci 27(22):59485957

33. Savidge TC, Sofroniew MV, Neunlist M (2007) Starring roles for astroglia in barrier pathologies of gut and brain. Lab Invest 87 (8):731-736

34. Ceyhan GO, Demir IE, Maak M, Friess H (2010) Fate of nerves in chronic pancreatitis: neural remodeling and pancreatic neuropathy. Best Pract Res Clin Gastroenterol 24(3):311-322

35. Bradley EL 3rd, Bem J (2003) Nerve blocks and neuroablative surgery for chronic pancreatitis. World J Surg 27(11):12411248

36. Leung JW, Bowen-Wright M, Aveling W, Shorvon PJ, Cotton PB (1983) Coeliac plexus block for pain in pancreatic cancer and chronic pancreatitis. Br J Surg 70(12):730-732

37. Wong GY, Sakorafas GH, Tsiotos GG, Sarr MG (1999) Palliation of pain in chronic pancreatitis. Use of neural blocks and neurotomy. Surg Clin North Am 79(4):873-893

38. Madsen P, Hansen E (1985) Coeliac plexus block versus pancreaticogastrostomy for pain in chronic pancreatitis. A controlled randomized trial. Scand J Gastroenterol 20(10):12171220

39. Owitz S, Koppolu S (1983) Celiac plexus block: an overview. Mt Sinai J Med 50(6):486-490

40. Buchler MW, Friess H, Bittner R, Roscher R, Krautzberger W, Muller MW, Malfertheiner P, Beger HG (1997) Duodenumpreserving pancreatic head resection: long-term results. J Gastrointest Surg 1(1):13-19

41. Buchler MW, Friess H, Muller MW, Wheatley AM, Beger HG (1995) Randomized trial of duodenum-preserving pancreatic head resection versus pylorus-preserving Whipple in chronic pancreatitis. Am J Surg 169(1):65-69, discussion 69-70

42. Koninger J, Friess H, Muller M, Buchler MW (2004) Duodenum preserving pancreatic head resection in the treatment of chronic pancreatitis. Rocz Akad Med Bialymst 49:53-60 
43. Koninger J, Seiler CM, Wente MN, Reidel MA, Gazayakan E, Mansmann U, Muller MW, Friess H, Buchler MW (2006) Duodenum preserving pancreatectomy in chronic pancreatitis: design of a randomized controlled trial comparing two surgical techniques [ISRCTN50638764]. Trials 7:12

44. Muller MW, Friess H, Beger HG, Kleeff J, Lauterburg B, Glasbrenner B, Riepl RL, Buchler MW (1997) Gastric emptying following pylorus-preserving Whipple and duodenum-preserving pancreatic head resection in patients with chronic pancreatitis. Am J Surg 173(4):257-263

45. Muller MW, Friess H, Leitzbach S, Michalski CW, Berberat P, Ceyhan GO, Hinz U, Ho CK, Koninger J, Kleeff J, Buchler MW (2008) Perioperative and follow-up results after central pancreatic head resection (Berne technique) in a consecutive series of patients with chronic pancreatitis. Am J Surg 196(3):364-372

46. Muller MW, Friess H, Martin DJ, Hinz U, Dahmen R, Buchler MW (2008) Long-term follow-up of a randomized clinical trial comparing Beger with pylorus-preserving Whipple procedure for chronic pancreatitis. Br J Surg 95(3):350-356

47. Ceyhan GO, Deucker S, Demir IE, Erkan M, Schmelz M, Bergmann F, Muller MW, Giese T, Buchler MW, Giese NA, Friess H (2009) Neural fractalkine expression is closely linked to pain and pancreatic neuritis in human chronic pancreatitis. Lab Invest 89(3):347-361

48. Koziolek MJ, Schmid H, Cohen CD, Blaschke S, Hemmerlein B, Zapf A, Muller GA, Strutz F (2007) Potential role of fractalkine receptor expression in human renal fibrogenesis. Kidney Int 72 (5):599-607

49. D'Haese JG, Demir IE, Friess H, Ceyhan GO (2010) Fractalkine/ CX3CR1: why a single chemokine-receptor duo bears a major and unique therapeutic potential. Expert Opin Ther Targets 14(2):207-219

50. Wasmuth HE, Zaldivar MM, Berres ML, Werth A, Scholten D, Hillebrandt S, Tacke F, Schmitz P, Dahl E, Wiederholt T, Hellerbrand C, Berg T, Weiskirchen R, Trautwein C, Lammert F (2008) The fractalkine receptor CX3CR1 is involved in liver fibrosis due to chronic hepatitis C infection. J Hepatol 48(2):208215

51. Demir IE, Ceyhan GO, Rauch U, Altintas B, Klotz M, Muller MW, Buchler MW, Friess H, Schafer KH (2010) The microenvironment in chronic pancreatitis and pancreatic cancer induces neuronal plasticity. Neurogastroenterol Motil 22(4):480-490, e112-483

52. Devor M (2006) Centralization, central sensitization and neuropathic pain. Focus on "sciatic chronic constriction injury produces cell-type-specific changes in the electrophysiological properties of rat substantia gelatinosa neurons". J Neurophysiol 96(2):522-523

53. Sandkuhler J (2009) Models and mechanisms of hyperalgesia and allodynia. Physiol Rev 89(2):707-758

54. Coderre TJ, Katz J (1997) Peripheral and central hyperexcitability: differential signs and symptoms in persistent pain. Behav Brain Sci 20(3):404-419, discussion 435-513

55. Pedersen JL, Andersen OK, Arendt-Nielsen L, Kehlet H (1998) Hyperalgesia and temporal summation of pain after heat injury in man. Pain 74(2-3):189-197

56. Dimcevski G, Staahl C, Andersen SD, Thorsgaard N, FunchJensen P, Arendt-Nielsen L, Drewes AM (2007) Assessment of experimental pain from skin, muscle, and esophagus in patients with chronic pancreatitis. Pancreas 35(1):22-29

57. Dimcevski G, Schipper KP, Tage-Jensen U, Funch-Jensen P, Krarup AL, Toft E, Thorsgaard N, Arendt-Nielsen L, Drewes AM (2006) Hypoalgesia to experimental visceral and somatic stimulation in painful chronic pancreatitis. Eur J Gastroenterol Hepatol 18(7):755-764

58. Bernstein CN, Niazi N, Robert M, Mertz H, Kodner A, Munakata J, Naliboff B, Mayer EA (1996) Rectal afferent function in patients with inflammatory and functional intestinal disorders. Pain 66(2-3):151-161

59. Mertz H, Fullerton S, Naliboff B, Mayer EA (1998) Symptoms and visceral perception in severe functional and organic dyspepsia. Gut 42(6):814-822

60. Buscher HC, Wilder-Smith OH, van Goor H (2006) Chronic pancreatitis patients show hyperalgesia of central origin: a pilot study. Eur J Pain 10(4):363-370

61. Winston JH, He ZJ, Shenoy M, Xiao SY, Pasricha PJ (2005) Molecular and behavioral changes in nociception in a novel rat model of chronic pancreatitis for the study of pain. Pain 117(12):214-222

62. Le Bars D, Villanueva L, Bouhassira D, Willer JC (1992) Diffuse noxious inhibitory controls (DNIC) in animals and in man. Patol Fiziol Èksp Ter 4:55-65

63. Villanueva L, Le Bars D (1995) The activation of bulbo-spinal controls by peripheral nociceptive inputs: diffuse noxious inhibitory controls. Biol Res 28(1):113-125

64. Vera-Portocarrero LP, Xie JY, Kowal J, Ossipov MH, King T, Porreca F (2006) Descending facilitation from the rostral ventromedial medulla maintains visceral pain in rats with experimental pancreatitis. Gastroenterology 130(7):2155-2164

65. Olesen SS, Brock C, Krarup AL, Funch-Jensen P, Arendt-Nielsen L, Wilder-Smith OH, Drewes AM (2010) Descending inhibitory pain modulation is impaired in patients with chronic pancreatitis. Clin Gastroenterol Hepatol 8(8):724-730

66. Dimcevski G, Sami SA, Funch-Jensen P, Le Pera D, Valeriani M, Arendt-Nielsen L, Drewes AM (2007) Pain in chronic pancreatitis: the role of reorganization in the central nervous system. Gastroenterology 132(4):1546-1556

67. Gucer G, Niedermeyer E, Long DM (1978) Thalamic EEG recordings in patients with chronic pain. J Neurol 219(1):47-61

68. Fregni F, Pascual-Leone A, Freedman SD (2007) Pain in chronic pancreatitis: a salutogenic mechanism or a maladaptive brain response? Pancreatology 7(5-6):411-422

69. Eisenach JC, Carpenter R, Curry R (2003) Analgesia from a peripherally active kappa-opioid receptor agonist in patients with chronic pancreatitis. Pain 101(1-2):89-95

70. Fregni F, Potvin K, Dasilva D, Wang X, Lenkinski RE, Freedman SD, Pascual-Leone A (2010) Clinical effects and brain metabolic correlates in non-invasive cortical neuromodulation for visceral pain. Eur J Pain doi:10.1016/j.ejpain.2010.08.002

71. Balasubramanyan S, Stemkowski PL, Stebbing MJ, Smith PA (2006) Sciatic chronic constriction injury produces cell-typespecific changes in the electrophysiological properties of rat substantia gelatinosa neurons. J Neurophysiol 96(2):579-590

72. Hesse H (1971) Lektüre für Minuten. Suhrkamp Verlag, Frankfurt 